\title{
INCREASING CO-RADIANT FUNCTIONS AND HERMITE-HADAMARD TYPE INEQUALITIES
}

\author{
G. R. ADILOV
}

Abstract. In this paper, we study Hermite-Hadamard type inequalities for increasing co-radiant functions. Some examples of such inequalities for functions defined on a special domains are given.

Mathematics subject classification (2010): 26D15, 26D07, 39B62.

Keywords and phrases: Hermite-Hadamard inequalities, functional inequalities, co-radiant functions, abstract convexity.

\section{REFERENCES}

[1] G. R. Adilov and S. Kemali, Hermite-Hadamard-Type Inequalities for Increasing Positively Homogeneous Functions, Journal of Inequalities and Applications, Vol. 2007, Article ID 21430, 10 pages, 2007.

[2] S. S. Dragomir, J. Dutta, And A. M. Rubinov, Hermite-Hadamard type inequalities for increasing convex along rays functions, Analysis (Munich), 24, 2, 171-181.

[3] S. S. Dragomir And C. E. M. Pearce, Selected Topics on Hermite-Hadamard Inequalities and Applications, RGMIA Monographs, Victoria University, 2000 [ONLINE: http: / / rgmia.vu.edu.au/monographs].

[4] S. S. Dragomir AND C. E. M. Pearce, Quasi-convex functions and Hadamard's inequality, Bull. Australian Math. Soc., 57 (1998), 377-385.

[5] S. S. Dragomir, J. E. Pecaric, and L. E. Persson, Some Inequalities of Hadamard Type, Soochow J. of Math., 21 (1995), 335-341.

[6] P. M. Gill, C. E. M. PearCe, And J. E. PeCaric, Hadamard's Inequalities for $r$-convex functions, J. Math. Anal. Appl., 215 (1997), 461-470.

[7] C. P. Niculescu, A multiplicative mean value and its applications, in Inequality theory and applications (Y. J. Cho, J. K. Kim and S. S. Dragomir (Eds.)), Nova Science Publishers, 2001, 249-261.

[8] C. E. M. Pearce And A. M. Rubinov, P-functions, quasiconvex functions and Hadamard-type inequalities, Journal of Mathematical Analysis and Applications, 240 (1999), 92-104.

[9] J. E. Pecaric, F. Proschan, And Y. L. Tong, Convex Functions, Partial Orderings and Statistical Applications, Academic Press Inc. 1992.

[10] A. M. Rubinov, Abstract convexity and global optimization, Kluwer Academic Publishers, Dordrecht, 2000.

[11] A. M. Rubinov And J. DutTa, Hadamard Type Inequality For Quasiconvex Functions in Higher Dimensions, (Preprint) RGMIA Res. Rep. Coll., 4, 1 (2001), Article 9.

[ONLINE: http://rgmia.vu.edu.au/v4n1.htm1]

[12] E. V. SHARIKOV, Hermite-Hadamard Type Inequalities for Increasing Radiant Functions, Journal of Inequalities in Pure and Applied Mathematics, 4, 2 (2003), Article 47. 